REVISTA DE DERECHO UNED, NÚM. 12, 2013

\title{
LA PROTECCIÓN JUDICIAL EN EL SISTEMA PENITENCIARIO MILITAR ESPAÑOL*
}

\section{JUDICIAL PROTECTION IN THE SPANISH MILITARY PRISON SYSTEM}

\author{
Juan Victorio SerRano Patiño
}

Abogado. Alumno doctorado de la UNED

"Administrad la justicia con ecuanimidad y rectitud y, si es necesario, con rigor y ejemplaridad. Pero cuando la naturaleza de las gentes y las cosas lo permitan, sed misericordiosos y benignos»

Felipe II

"Bienaventurado el que dejando aparte su gusto e inclinación, mira las cosas en razón y justicia para hacerlas»

San Juan de la Cruz

Resumen: El ingreso en una prisión militar española origina el nacimiento de una relación de especial sujeción sin que el sistema penitenciario militar español pueda impedir el ejercicio de acciones judiciales ante los abusos y desviaciones que puedan producirse por cuando el interno sigue siendo sujeto de derecho y no objeto. El presente trabajo hace un estudio del Juez de Vigilancia en el ámbito castrense y sus funciones, los recursos judiciales que tiene el interno en el ámbito penitenciario militar y aporta soluciones ante vacíos legales para concluir haciendo una valoración final del sistema.

Abstract: Admission to a Spanish military prison originates the birth of a special relationship of submission without the Spanish mi-

* Especial agradecimientos a mi familia, al profesor don Fernando Reviriego Picón, a la UNED y a mi amigo Luismi, siempre dispuesto. 
litary prison system to prevent the exercise of judicial actions against the abuses and deviations that may occur for when the inmate is still a subject of law and order. This paper makes a study of the supervising judge in the military realm and its functions, judicial resources has the domestic military court in the prison in the field and provides solutions to legal loopholes to conclude with a final assessment of the system.

Palabras clave: Sistema penitenciario militar español, protección legal, garantías legales, recursos, procedimiento, abusos, desviaciones, Juez de Vigilancia Penitenciaria, interpretaciones, lagunas legales, soluciones y valoración.

Keywords: Spanish military prison system, legal protection, due process, resources, procedures, abuse, diversion, Judge prison supervision interpretations loopholes and assessment solutions.

Recepción original: 26/04/2013

Aceptación original: 29/04/2013

Sumario: I. Justificación del tema. II. Garantías en el iter criminis. III. El Juez de Vigilancia. IV. Funciones del Juez de Vigilancia Militar. V. Argumentaciones ante vacíos legales y otras interpretaciones. VI. Conclusiones. VII. Referencias bibliográficas. VIII. Abreviaturas utilizadas.

\section{JUSTIFICACIÓN DEL TEMA}

El sistema penitenciario militar español se articula con el RPM ${ }^{1}$ pero teniendo esta norma un carácter meramente reglamentario debe de apoyarse necesariamente para no entrar en colisión frontal ${ }^{2}$ con el orden constitucional con otras normas de igual o superior carácter al de Ley formal.

El origen del RPM se encuentra en el art. 348 de la $\mathrm{LPM}^{3}$ que establece que «las penas que deban cumplirse en establecimientos

1 El RPM fue aprobado por RD 1396/ 1992, de 20 de noviembre, publicado en el BOE. núm. 305, de 21 de diciembre de 1992, disponiendo su Disposición Final Segunda que entraría en vigor el 1 de enero de 1993.

2 La CE en su artículo 81 establece una clara reserva de Ley orgánica para el desarrollo de los derechos fundamentales y de las libertades públicas y, por otro lado, el art. 53.1 de la norma fundamental contempla también una reserva de ley ordinaria en relación con los derechos y libertades reconocidas en el Capítulo II del Título I.

3 LO 2/1989, de 13 de abril. 
penitenciarios militares de acuerdo con el citado artículo $42^{4}$, se cumplirán conforme a lo dispuesto en esta Ley y en el Reglamento de Establecimientos Penitenciarios Militares, que se inspirará en los principios de la Ley Orgánica General Penitenciaria acomodados a la especial estructura de las Fuerzas Armadas y con observancia en todo caso de las sanciones previstas en los cinco primeros apartados del artículo 42 de dicha Ley».

De todo ello se colige que, como quiera que la relación de especial sujeción que surge con la entrada de un interno en un EPM implica un entramado de derechos y deberes, el sistema exige en todo caso una clara reserva de la Ley, por lo que dado el carácter reglamentario del RPM, el sistema penitenciario militar debe apoyarse necesariamente en la CE, el CPM ${ }^{5}$, la LPM, la $\mathrm{LOGP}^{6}$ y en el $\mathrm{RP}^{7}$.

Según Claver Valderas ${ }^{8}$ el Reglamento de Establecimientos Penitenciarios Militares podría conllevar a que se declarase la inconstitucional formal del mismo por incumplimiento de la reserva de Ley. Sin embargo explica que «esta interpretación no puede ser pues a mi juicio la correcta. El citado reglamento lo que de verdad ha venido a desarrollar para el ámbito militar no es solo la Ley procesal militar sino fundamentalmente la ley orgánica general penitenciaria...»

Por otro lado, el reconocimiento constitucional de la jurisdicción militar ${ }^{9}$ en ningún caso convierte a la administración castrense bajo

4 El art. 42 del CPM señala que «Las penas de privación de libertad impuestas a militares por delitos comprendidos en este Código se cumplirán en el establecimiento penitenciario militar que se determine por el Ministerio de Defensa.

En caso que las penas impuestas a militares por la comisión de delitos comunes lleven consigo la baja en las Fuerzas Armadas, se extinguirán en establecimientos penitenciarios ordinarios, con separación del resto de los penados. Si no llevan aparejada la baja en las Fuerzas Armadas, se cumplirán en el establecimiento penitenciario militar que se disponga por el Ministerio de Defensa».

5 LO 13/1985, de 9 de diciembre.

6 LO 1/1979, de 26 de septiembre.

7 RD 190/1996, de 9 de febrero, y en vigor conforme con la Disposición Derogatoria única, los arts. 108, 109, 110 y 111 y del primer párrafo del art. 124 del RP, aprobado por RD 1201/ 1981, de 8 de mayo, en la redacción dada por el RD $787 / 1984$, de 26 de marzo, relativos a las faltas o infracciones de los internos, a las sanciones disciplinarias y a los actos de indisciplina grave cuya sanción puede ser inmediatamente ejecutada.

8 Claver Valderas, José Manuel. Comunicación. aplicabilidad de penas por el trabajo a los internos en establecimientos penitenciarios militares. Derecho Penal y Procesal Militar. Consejo General del Poder Judicial. 1993, pág. 766.

9 El art. 117.5 de la CE de 1978 dice «El principio de unidad jurisdiccional es la base de la organización y funcionamiento de los Tribunales. La Ley regulará el ejercicio de la jurisdicción militar en el ámbito estrictamente castrense y en los supuestos de estado de sitio, de acuerdo con los principios de la Constitución». 
excusa de su propia especialidad en un compartimiento estanco dentro del Ordenamiento Jurídico Español. Una cosa es el reconocimiento de la especialidad militar y otra que ésta pueda sustraerse del sistema de garantías constitucionales diseñado por la propia CE.

Y sentado lo anterior, puede afirmarse que si no hay un control judicial en la aplicación de los actos de la administración penitenciaria militar ${ }^{10}$, el sistema penitenciario militar español carecería de credibilidad, además de situarse fuera del Estado de Derecho. ${ }^{11} \mathrm{Y}$ la $\mathrm{CE}$, en este sentido, no distingue entre administraciones cuando señala en su art. 106.2 que «Los Tribunales controlan la potestad reglamentaria y la legalidad de la actuación administrativa, así como el sometimiento de ésta a los fines que la justifican».

Y así dejadas estas bases, el presente trabajo pretende servir de reflexión sobre si el sistema judicial castrense resulta adecuado para el sistema penitenciario militar español así como la forma de suplir los vacíos legales detectados con soluciones adecuadas y acordes con el derecho a la tutela judicial efectiva.

\section{GARANTÍAS EN EL ITER CRÍMINIS}

En el camino que discurre desde la existencia de un delito a la ejecución de la pena privativa de libertad que corresponda, podemos distinguir varias garantías que tienen en común el sometimiento al estricto principio de legalidad ${ }^{12}$. A saber:

- La garantía criminal según la cual no existe delito sin que una ley anterior lo haya previamente tipificado ${ }^{13}$.

10 Normalmente los órganos judiciales, conocerán de las quejas y recursos formulados por los internos, lo que no impide la facultad que tienen estos de vigilar o controlar el buen funcionamiento de la administración penitenciaria militar.

11 Resulta esclarecedoras las palabras recogidas en la exposición de motivos de la Ley de la Jurisdicción Contenciosa Administrativa, aprobada por Ley 29/1998, de 13 de Julio, cuando señala «Sería ciertamente un contrasentido que una Ley que pretende adecuar el régimen legal de la Jurisdicción Contencioso-Administrativa a la letra y al espíritu de la Constitución, llevase a cabo la introducción de toda una esfera de actuación gubernamental inmune al derecho. En realidad, el propio concepto de "acto político» se halla hoy en franca retirada en el Derecho público europeo. Los intentos encaminados a mantenerlo, ya sean delimitando genéricamente un ámbito en la actuación del poder ejecutivo regido sólo por el Derecho Constitucional, y exento del control de la Jurisdicción Contencioso-administrativa, ya sea estableciendo una lista de supuestos excluidos del control judicial, resultan inadmisible en un Estado de Derecho».

12 El art. 9.3 de la CE señala que la Constitución garantiza el principio de legalidad.

13 Se contempla en el art. 25.1 de la CE, 1.1 del CP y en el art. 4 del CPM. 
- La garantía penal que impide imponer una pena por delito que no haya sido establecida en la Ley ${ }^{14}$.

- La garantía jurisdiccional ${ }^{15}$ por la que nadie puede ser condenado sino en virtud de Sentencia firme dictada por Tribunal competente, sometido únicamente al imperio de la Ley y el derecho.

- La garantía ejecutiva ${ }^{16}$ que implica que no podrá ser ejecutada pena alguna distinta de la prevista en la Ley y los Reglamentos.

Dejando las dos primeras garantías penales propiamente dichas, nos centraremos en las atinentes a las de naturaleza penitenciaria propiamente castrense.

Así el art. 338 de la LPM contempla la garantía jurisdiccional y ejecutiva, señalando que «las penas impuestas en Sentencias firmes dictadas en la jurisdicción militar se ejecutarán conforme se establezca en la Sentencia y en la forma que dispongan las Leyes y Reglamentos ${ }^{17}$ ».

El art. 348 de la LPM, abundando en la garantía ejecutiva, señala que las penas que deban cumplirse en establecimientos penitenciarios militares de acuerdo con el art. 42 del CPM, se cumplirán conforme con lo dispuesto en esta Ley y en el RPM.

Por su parte, el art. 5 del CPM reseña que «las disposiciones del Código Penal serán aplicables a los delitos militares en cuanto lo permita su especial naturaleza y no se opongan a los preceptos del presente Código».

Y en fin, señalar que el art. 43 del CPM afirma que «en tiempo de guerra, las penas privativas de libertad impuestas a militares podrán ser cumplidas en funciones que el mando militar designe, en atención a las exigencias de la campaña y de la disciplina».

\section{EL JUEZ DE VIGILANCIA}

El Juez de Vigilancia Penitenciaria es una figura clave en el sistema penitenciario ${ }^{18}$, garante de los derechos de los internos y

14 Se contempla en el art. 2.1 del CP así como en los arts. 4 y 20 del CPM.

15 Se contempla en el art. 3.1 del CP.

16 Se contempla en el art. 3.2 del CP.

17 El art. 990, párrafo primero de la LECrim señala que «las penas se ejecutarán en la forma y tiempo prescritos en el Código Penal y en los Reglamentos».

18 La STS de 20 de diciembre de 1993, recaída en un conflicto de jurisdicción afirmó que «El Juez de Vigilancia Penitenciaria-pieza básica del sistema-ostenta por 
como órgano integrante del poder judicial, independiente del poder ejecutivo $^{19}$, puede poner remedio a los abusos y desviaciones que se puedan producirse en el sistema penitenciario.

La figura del JVP se judicializó con la LOGP al integrarse en el Poder Judicial presentando los mismos matices en el ámbito castrense desde 1987, lo que representó un gran avance si se piensa que en el RPM de 1978 -que fue derogado por el actual RPM de 1992- estas funciones se encomendaban al Capitán General con su auditor.

La LOCO atribuyó a los juzgados Togados Militares Territoriales la competencia de la vigilancia penitenciaria, lo que dio lugar al nacimiento de la OM 44/ 1988, de 30 de mayo a fin de adaptar el sistema penitenciario militar a las nuevas exigencias.

Pero esta regulación resultaba insuficiente, por lo que la Sala de Gobierno del Tribunal Militar Central, en uso de las facultades que le confería el artículo 35 de la LOCO, acordó proponer una nueva modificación, la que se efectuaría finalmente por OM 29/1989, de 28 de marzo, dejando sentado el criterio que las referencias al Capitán General de la Región Militar o Zona Marítima se entenderán hechas al Juez Togado Militar Territorial de la demarcación donde se ubique el establecimiento penitenciario o, cuando hubiera varios, por el Juez Togado que le siga en antigüedad al que ostenta el Decanato de dichos Jueces Togados Militares.

Anteriormente ya señalamos que la LOCO atribuyó funciones de vigilancia penitenciaria a los Juzgados Togados Territoriales pero no fue sino la LPM la que formalmente les daría en el ámbito castrense tal denominación.

Así, el art. 356 de la LPM establece que en cada establecimiento penitenciario militar habrá un Juez de Vigilancia ${ }^{20}$, cargo que será ejercido por el Juez Togado Militar que designe la Sala de Gobierno del Tribunal Militar Central y cuyas funciones serán compatibles con el desempeño de un órgano jurisdiccional y en el caso que se estime

exigencias inherentes a las formulaciones constitucionales un ámbito jurisdiccional que encuentra su raíz en el artículo 117 de la Constitución».

19 El art. 117.1 de la CE establece que «la justicia emana del pueblo y se administra por Jueces y magistrados independientes, responsables y sujetos únicamente al imperio de la Ley y el derecho».

20 Actualmente, solo existe un JVP con sede en Madrid y en compatibilidad con otras funciones de Juzgado Togado Militar Territorial n. ${ }^{\circ} 11$ o 12, según proceda. Se corresponde con la demarcación del EPM de Alcalá de Henares, actualmente el único existente. El EPM de la Isleta, en las Palmas de Gran Canaria, coexistía con el de Alcalá de Henares desde 1989 hasta que oficialmente fue cerrado el 1 de febrero de 1995, según consta en la estadística de la jurisdicción militar del año 2010. 
por la indicada Sala de Gobierno que las funciones deban de ser exclusivas lo propondrá al Ministerio de Defensa.

De igual manera se señala en este artículo que el cese o suspensión de estas funciones se regirá por los arts. 66 y 67 de la LOCO, lo que a mi juicio resulta innecesario ya que sería igualmente de aplicación si no se hubiera recogido.

La figura del Juez de Vigilancia aparece reflejada en los arts. 76 a 79 de la LOGP; en los art. 94 y 95 de la LOPJ; Y en el art. 61.4 de la LOCO que señala como función de los Juzgados Togados Militares Territoriales «la vigilancia penitenciaria en relación con los establecimientos penitenciarios militares y sus internos»; en los arts. 356 a 358 de LPM y, en fin en el art. 36 del RPM.

El art. 36 del RPM señala claramente que el Juez de Vigilancia tendrá la competencia y funciones que le atribuyen la LOGP y la LPM.

Desde un punto de vista orgánico, no cabe duda, teniendo en cuenta el art. 1 de la $\mathrm{LOCO}^{21}$ que el juez militar es integrante del Poder Judicial y por consiguiente también lo es el Juez Togado Militar territorial que asume las funciones de vigilancia penitenciaria.

FERNÁNDEZ BENITO ${ }^{22}$ afirma que «de los grandes principios constitucionales, en lo aplicable a la jurisdicción ordinaria, se deriva la normativa contenida en la Ley Orgánica del Poder Judicial (LOPJ) y en la militar, aparecen desarrollados en la Ley Orgánica 4/1987, de 15 de julio, de Competencia y Organización de la Jurisdicción Militar (LOCO). Así los juzgados militares se integran en el Poder judicial del Estado (artículo 117.1 C-artículo 1 LOCO); son independientes (artículo 117.1 C-artículo 6 LOCO); responsables y sometidos únicamente al imperio de la Ley (artículo 117.1 y 2 C-artículo 6 y 8 LOCO); ningún órgano público puede ejercer sus funciones (artículo 117.3 C-artículo 2 LOCO); no puede encargarse al personal que sirve en los órganos judiciales la realización de funciones públicas distintas de las propias del Poder Judicial (artículo 117.4 C-artículo 119, párrafo segundo LOCO); entre otras muchas».

Sin embargo la figura del Juez en el ámbito castrense presenta unos caracteres un tanto peculiares: Por un lado, sus miembros

21 Señala el art. 1 de la LOCO que «La jurisdicción militar, integrante del poder judicial del Estado, administra justicia en nombre del Rey, con arreglo a los principios de la Constitución y a las Leyes».

22 Fernández Benito, Alfredo. Comunicación. La determinación del Estatuto Personal de Vocales y Jueces Togados: Un imperativo constitucional. La jurisdicción Militar. Consejo General del Poder Judicial. 1992, pág. 158. 
forman parte del Poder Judicial pero por el otro, no dejan de ser militares en activo, con empleo o rango propio en el ámbito castrense.

En cualquier caso, los jueces militares no parece que se encuentren representados en el Consejo General del Poder Judicial que es el órgano de Gobierno de los Jueces y Magistrados, como se sabe.

Seguidamente trataremos de enfocar la cuestión para precisar más detalladamente esta figura.

Son integrantes del Poder Judicial pero también forman parte del Cuerpo Jurídico Militar y de forma especial la Ley 39/2007, de 19 de noviembre de la Carrera Militar, en su art. 26. 4 los engloba en los cuerpos comunes de las FFAA, señalando el art. 37 relativo al Cuerpo Jurídico Militar, lo que sigue:

1. Los miembros del Cuerpo Jurídico Militar, agrupados en una escala de oficiales, tienen como cometidos los de asesoramiento jurídico y los que conforme al ordenamiento jurídico les correspondan en la jurisdicción militar.

2. Los empleos del Cuerpo Jurídico Militar son los de teniente a coronel, con las denominaciones del empleo correspondiente seguidas del termino auditor, y los de general de brigada y general de división, con las denominaciones de general auditor y general consejero togado, respectivamente.

Si seguimos profundizando en Ley de la Carrera Militar constataremos que mientras ejerzan funciones correspondientes a la jurisdicción militar se los sitúa dentro del servicio activo y, sin embargo, este texto legal en su art. 109. 1g) señala que se encontrarán en la situación de servicios especiales los militares cuando presten servicios en el TS o en otros órganos jurisdiccionales y en su n. ${ }^{\circ} 2$ señala que percibirán la retribución del puesto o cargo que ocupen y no las que les corresponda como militares profesionales, sin perjuicio de los trienios que tuvieran reconocidos.

De todo lo dicho, se deduce que los miembros del Cuerpo Jurídico Militar -en concreto y literalmente se reseña a los militares de carrera y los militares de tropa y marinería con compromiso de larga duración- cuando realizan funciones judiciales en órganos castrenses son militares profesionales con nómina en el Ministerio de Defensa, en tanto si desempeñan funciones en el TS o en otros organismos jurisdiccionales de la jurisdicción ordinaria pasarán a una situación administrativa especial denominada servicios especiales que implica que se les suspende el carácter de militares durante el 
tiempo que duren dichos servicios y, por otro lado, ya no percibirán sus honorarios del Ministerio de Defensa sino del órgano en el que ejerzan sus funciones.

Pues bien, en una primera aproximación, parece que el juez Togado se aproxima más a un órgano de carácter administrativo que judicial y se nos ocurre que muy semejante a los magistrados que integran los llamados Tribunales económico administrativos ${ }^{23}$ y sólo si están destinados en los órganos propiamente judiciales ordinarios gozarán integralmente de tal status, al tener plena independencia orgánica y funcional. Así a mi juicio esta independencia la tendrá un general auditor destinado en la Sala V «de lo militar» del Tribunal Supremo pero no la tendría con la misma plenitud si formara parte, por ejemplo, de un Tribunal Militar Territorial o del propio Tribunal Militar Central.

Y dicho lo anterior, debemos entender que los Jueces Togados con funciones de vigilancia penitenciaria se encontrarán en la situación administrativa de servicio activo, formando parte del Cuerpo Jurídico Militar, que es un Cuerpo Común de las FFAA como ya hemos visto y, por lo tanto, compaginarán las funciones del empleo militar y las de la función jurisdiccional castrense.

$\mathrm{Y}$ así las cosas, consideramos que salvo en circunstancias excepcionales como pudiera ser el estado de excepción o sitio o en tiempo de guerra ${ }^{24}$, lo que pudiera justificar una situación anormal para casos excepcionales, no podemos entender que las funciones de vigilancia penitencia queden en manos de un órgano administrativo en el sentido que venimos exponiendo sin que haya una merma al menos potencial para los derechos de los internos, por lo que de lege ferenda, abogamos que en circunstancias de plena normalidad dichas funciones residan en los propios juzgados de Vigilancia Penitenciaria Ordinarios.

23 Los magistrados que componen los distintos Tribunales Económico administrativos, como el Tribunal Económico Central, regional o municipales en general, no son propiamente magistrados sino miembros de órganos puramente administrativos, aunque para la administración son vinculantes sus resoluciones. Ahora bien, aunque se hable de Tribunales, propiamente no lo son.

${ }_{24}$ Prefiero utilizar el término tiempo de guerra al de declaración de guerra. Así lo hace el art. 13 de LOCO cuando señala su competencia en «tiempo de guerra» y en el ámbito que determine el Gobierno, en lugar de «declaración de guerra», ya que en esta situación no caben formalismos, como se constaría al inicio de la segunda guerra mundial. En cualquier caso, la utilización del término «declaración de guerra» se contempla en el art. 63 de la CE. que señala que corresponde al Rey, previa autorización de las Cortes, declarar la guerra y hacer la paz.

Esta situación aparece en el art. 116.4 de la CE y se regula en la LO 4/1981, de 1 de junio, de los estados de alarma, excepción y sitio. 
Entendemos que los derechos que puede tener un interno en un EPM quedarían mejor salvaguardados, si el órgano de enjuiciamiento con facultades decisorias en la materia perteneciera orgánicamente a otro Ministerio, distinto al de Defensa ${ }^{25}$.

Por otro lado, si bien el Juez Togado pertenece a los cuerpos comunes del ejército, no por ello pierde su empleo y rango, y en este sentido podemos reflexionar que siendo el Director del EPM un Coronel para que se diera una situación de plenitud o de igual jerarquía, el cargo del JVPM lo debería de asumir un general o coronel con mayor antigüedad al Coronel rector del EPM, lo que en la práctica no se produce.

Por el Juzgado Togado Militar Territorial n. ${ }^{\circ} 11$, ó 12 según proceda $^{26}$, han pasado Jueces Togados con la categoría de teniente coronel, comandante y hasta últimamente el de capitán, que son empleos inferiores al de coronel. Así las cosas, en una institución tan jerarquizada como es el Ejército, se nos antoja una dificultad añadida el desempeño funciones de la jurisdicción militar que pudieran implicar la anulación de actos emanados por un superior jerárquico, lo que en el EPM es un hecho, dado el carácter presidencialista que tiene la figura del Coronel Director del EPM.

Todas estas objeciones, entiendo que se disiparían, si fuera un órgano judicial ordinario ${ }^{27}$ el que conociera de los recursos, quejas

25 El art. 4 del RPM adscribía los EPM a la Secretaría del Estado del Ministerio de Defensa, la que determinará su número y ubicación y facilitará los medios personales, materiales y económicos para su adecuado funcionamiento, artículo que sería formalmente derogado por la Disposición Derogatoria Única del RD 915/2002, de 6 de septiembre, sobre Organización y Funcionamiento de las Delegaciones de Defensa (BOE núm. 215, de 7 de septiembre) que dispone en su disposición adicional $3{ }^{\mathrm{a}}$

1. A la entrada en vigor del presente Real Decreto, el establecimiento penitenciario militar de Alcalá de Henares quedará adscrito directamente a la Subsecretaría de Defensa, con dependencia orgánica y funcional de la misma a todos los efectos.

2. Lo dispuesto en el apartado anterior se entiende sin perjuicio de las funciones que corresponden a la Asesoría Jurídica General de la Defensa para asistir a la Subsecretaría del Departamento en el estudio, preparación y ejecución de cuantos asuntos se le encarguen relativos a la administración penitenciaria militar.

El RD 915/2002 estaría vigente hasta el 16 de marzo de 2007, al quedar derogado a su vez, por el todavía en vigor, RD 308/2007, de 2 de marzo, sobre organización y funcionamiento de las Delegaciones de Defensa (BOE núm. 64, de 15 de marzo de 2007).

26 Con sede en Madrid y al que corresponde resolver las reclamaciones e incidencias derivadas del único EPM existente en Alcalá de Henares.

27 La STC 2/87, de 21 de enero señala que lo que caracteriza por ser órgano judicial, independiente del poder administrativo, en quien el ordenamiento confía 
y reclamaciones que le formularan los internos en un EPM, que en la mayoría de los casos, lo serán frente a una denegación de un permiso de salida, frente a una sanción o una queja por mal funcionamiento de un servicio.

\section{FUNCIONES DEL JUEZ DE VIGILANCIA MILITAR}

Las funciones que corresponde al JVPM se recogen en el art. 357 de la LPM. Lo primero que debemos de señalar es que resulta clara su competencia sobre todos los internos, ya lo sean en calidad de detenidos, presos y penados, para la salvaguarda de sus derechos y poder corregir los abusos y desviaciones que en cumplimiento de los preceptos del régimen penitenciario puedan producirse, sin perjuicio de la autoridad y competencia que hubiera decretado el ingreso en prisión.

Les corresponde especialmente:

1. Adoptar todas las decisiones necesarias para que los pronunciamientos de las resoluciones en orden a las penas privativas de libertad se lleven a cabo, asumiendo las funciones que corresponderían a los Jueces y Tribunales sentenciadores.

2. ${ }^{\circ}$ Resolver sobre las propuestas de libertad condicional de los penados y acordar las revocaciones que procedan.

3. ${ }^{\circ}$ Aprobar las propuestas que formulen los establecimientos sobre beneficios penitenciarios que pueden suponer acortamiento de la condena.

4. ${ }^{\circ}$ Aprobar las sanciones de aislamiento en celda de duración superior a catorce días.

5. ${ }^{\circ}$ Resolver por vía de recurso las reclamaciones que formulen los internos sobre sanciones disciplinarias.

6..$^{\circ}$ Acordar lo que proceda sobre las peticiones y quejas que los internos formulen en relación con el régimen y el tratamiento penitenciario en cuanto afecte a los derechos fundamentales o a los derechos y beneficios penitenciarios de aquéllos.

7. ${ }^{\circ}$ Realizar las visitas a los establecimientos penitenciarios previstas en el RPM.

8. ${ }^{\circ} \quad$ Autorizar los permisos de salida cuya duración sea superior a dos días.

el control sobre la protección de los derechos de los internos, y que constituye pieza clave del sistema penitenciario. 
Asimismo de acuerdo con el art. 36 del RPM le corresponde formular propuestas al Ministerio de Defensa, referentes a la organización y desarrollo de los servicios de vigilancia, a la ordenación de la convivencia interior de los establecimientos, a la organización y actividades de los talleres, escuela, asistencia médica y, en general, a las actividades regimentales, económico-administrativas y de tratamiento penitenciario en sentido estricto.

El RPM concreta las visitas a los establecimientos señaladas en el n. ${ }^{\circ} 7$ del art. 357 de la LPM, señalando que las podrá realizar en cualquier momento por iniciativa propia o cuando sea requerido para ello pero que, en todo caso, tendrán una periodicidad mensual.

A modo final diremos que la regulación que de competencias se señala en el art. 357 de la LPM, coincide prácticamente y de forma casi literal con la prevista en el art. 76.2 de la LOGP, con las siguientes matizaciones:

1. ${ }^{\circ}$ Se suprime el apartado f) de la LOGP que señala resolver en base a los estudios de los Equipos de Observación y Tratamiento, y en su caso de la Central de Observación, los recursos referentes a clasificación inicial y a progresiones y regresiones de grado.

La explicación de esta diferencia la encontramos no en una especialidad puramente militar sino en el hecho que la LPM es posterior a la LOGP y posterior a la LOPJ que, como se sabe, había atribuido a los Tribunales Sentenciadores el conocimiento de las funciones señaladas en materia de clasificación.

2. $\quad$ En el apartado i) de la LOGP se contempla que no será necesaria la autorización del JVP para permisos superiores a dos días en clasificados en tercer grado.

La explicación, que hoy en día ya queda superada a favor de la LOGP, radica en el hecho que en el sistema penitenciario militar vigente y anterior al RPM -y que era el progresivo- no existían grados ni se contemplaba el régimen abierto.

3. ${ }^{\circ}$ Supresión del apartado j) de la LOGP relativo al conocimiento del pase a los establecimientos de régimen cerrado de los reclusos a propuesta del Director del Establecimiento.

Y no se establece esta cuestión debido al sistema progresivo que operaba en la tradición castrense, de manera que la LPM recogía en el consabido art. 348 que el futuro RPM se inspiraría en los principios de la LOGP pero sin querer configurar el sistema que en la prác- 
tica ha impuesto el sistema penitenciario común con el sistema de la individualización científica.

Y en fin, el art. 36 del RPM coincide literalmente con el previsto en el art. 77 de la LOGP, a excepción de que podrán dirigirse formulando propuestas a la Dirección General de Instituciones Penitenciarias, ya que en el sistema militar a quien tienen que dirigirse es al Ministerio de Defensa y también la supresión de la asistencia religiosa, por cuanto se había dispuesto que los Cuerpos Eclesiásticos del Ejército de Tierra, de la Armada y del Aire se declararan a extinguir conforme se señalaba en la Disposición final $7^{\mathrm{a}} .3$ de la Ley 17/89, de 19 de julio, reguladora del Régimen del Personal Militar Profesional.

\section{ARGUMENTACIONES ANTE VACÍOS LEGALES Y OTRAS INTERPRETACIONES}

Con arreglo al art. 356 de la LPM habrá un Juzgado de Vigilancia Penitenciaria por cada establecimiento penitenciario militar y ante el vacío de otros lugares en donde puede existir un militar internado preventivamente en los supuestos del art. $219^{28}$ de la LPM o incluso penado en los casos previstos en el art. $350^{29}$ de la LPM y del art. $14^{30}$ del RPM, nos planteamos a quienes corresponde la vigilancia, por-

28 El art. 219 de la LPM señala «Cuando un órgano de cualquier jurisdicción se hubiera acordado la prisión preventiva respecto de un militar en situación de actividad o reserva, la sufrirá en establecimiento penitenciario militar, interesándose por quien la hubiera acordado, su ejecución de la Autoridad Militar de quien dependa, la cual dará cumplimiento inmediatamente al requerimiento. En caso de que no existiere establecimiento de esta clase en la plaza o inmediaciones, se llevará a efecto en el acuartelamiento, base o buque militar que designe la Autoridad Militar que hubiere recibido el acuerdo. En todo caso ésta comunicará a la judicial correspondiente el lugar, día y hora de ejecución de lo acordado conforme a las condiciones que se expresen en su comunicación".

29 El art. 350 de la LPM señala «Para el cumplimiento de las penas privativas de libertad que deban cumplirse en establecimientos penitenciarios militares, el Tribunal solicitará del Ministerio de Defensa la designación del centro en que deba extinguirse. No se solicitará dicha designación cuando al condenado que ya estuviera privado de libertad le quedaren menos de dos meses para extinguir la condena impuesta, en cuyo caso permanecerá en el centro donde se encuentre hasta su cumplimiento».

30 El art. 14 del RPM señala que «El ingreso de los penados en el establecimiento que en cada caso designe el Director General de Personal del Ministerio de Defensa será ordenado por el órgano judicial competente una vez que la sentencia condenatoria sea firme. No obstante, si en el momento de adquirir firmeza la referida sentencia, le restase al interno hasta su liberación definitiva o condicional un tiempo de cumplimiento inferior a dos meses, podrá seguir destinado en la sección de preventivos o en el centro donde se encuentre». 
que lo cierto es que con arreglo al art. $221^{31}$ de la LPM el Jefe militar de la unidad en la que se encuentra el internado cuidará en lo posible un régimen equiparable al que se sigue en los EPM.

$\mathrm{Y}$ teniendo en cuenta que en estas unidades no existe ninguna especialización en la materia, nos planteamos que acaso en estas condiciones de internamiento pudieran producirse más abusos o desviaciones que las que pudieran existir en el EPM, de lo que se deduce que pudiera ser más necesario la posibilidad de plantear algún tipo de recurso o queja por parte del interno.

Dar respuesta a esta cuestión puede dar lugar a planteamientos distintos pero nunca puede existir un vacío en el Ordenamiento Jurídico, el que debe dar una respuesta a todas las cuestiones que le sean planteadas, de suerte que está fuera de toda duda que el internado en unidad tiene que tener derecho a plantear recursos o quejas ante un órgano judicial, ya que de lo contrario se causaría una indefensión injustificable, colocándosele en un limbo jurídico reñido con el derecho a la tutela judicial efectiva ${ }^{32}$.

En estos casos, se nos ocurre que si este militar está interno en dicha unidad por decisión de un Juez ordinario, lo que jurídicamente puede ser posible, y se producen abusos o situaciones objeto de tutela judicial efectiva, corresponderá conocer del recurso correspondiente al JVP de la demarcación en donde se encuentre, de acuerdo con los arts. 94 y 95 de la LOPJ como garante de los derechos fundamentales del interno.

Entiendo que esta es la decisión más lógica, ya que la autoridad que hubiera decretado su internamiento tendría competencias limitadas para las cuestiones derivadas de su situación personal e incluso en el caso de los penados que tuvieran que cumplir un escaso tiempo inferior a dos meses, asumirán las funciones derivadas de ejecución pero nunca las derivadas de recursos en materia de cumplimiento que residirían, como decimos, en el JVP competente al sitio donde radicase la Unidad militar en donde estuviera el interno.

31 Señala el art. 221 de la LPM que «La autoridad militar hará saber al Gobernador o Jefe del establecimiento en donde el militar sufra prisión preventiva, el Órgano judicial que la hubiera acordado y a cuya disposición queda el mismo, así como las demás condiciones en que deba cumplirse. Si la prisión preventiva se sufre en acuartelamiento, base o buque militar, el Jefe Militar que se encuentre al mando de los mismos cuidará que el preso preventivo observe, en lo posible, un régimen equiparable al que se sigue en establecimientos penitenciarios militares».

32 La CE de 1978 señala en el art. 24.1 que «todas las personas tienen derecho a obtener la tutela judicial efectiva de los jueces y tribunales en el ejercicio de sus derechos e intereses legítimos, sin que, en ningún caso, pueda producirse indefensión». 
Por el contrario si el internado en unidad militar lo está por delito militar, entiendo que la competencia residiría en el Juez Togado Militar Territorial que ejerza competencias sobre el lugar en donde se encuentre el interno, en base a lo establecido en el art. 61.4 de la LOCO en relación con el art. 356 de igual texto legal y la LPM.

El art. 358 de la LPM señala que «las resoluciones que dicten los Jueces de Vigilancia en materia de su competencia, como tales serán notificadas a los reclusos interesados y al Fiscal jurídico Militar del Tribunal Sentenciador. Contra dichas resoluciones podrá interponerse por el Fiscal o los reclusos recurso de apelación, que se presentará ante el propio Juez de Vigilancia que lo declarará admisible o inadmisible mediante auto. En el primer caso, lo elevará al Tribunal Militar Territorial encargado del cumplimiento de la Sentencia para su conocimiento y fallo; en el segundo caso, lo notificará y contra el auto que así lo declare se podrá acudir en queja ante el mismo Tribunal».

Del contenido del art. 358 de la LPM específicamente regulado contra las resoluciones dictadas por el JVP se pueden plantear, al menos desde el punto de vista teórico, varias controversias relativas a los recursos y a lo que se debe entender por Juez encargado del cumplimiento de la Sentencia.

Atendiendo a la primera de las cuestiones, el precepto citado contempla sólo el recurso de apelación y, en su caso, de queja por denegación de la admisión de éste pero no se regula el llamado recurso de reforma, omisión que bien pudiera parecer una primera diferencia importante con el sistema penitenciario común.

Sin embargo, por integración directa en el sistema penitenciario castrense de la disposición adicional quinta ${ }^{33}$ de la LOPJ, que sí prevé el mencionado recurso de reforma en su punto primero, resulta por lo tanto plenamente aplicable y actualmente no existe controversia alguna para la admisión del indicado recurso de reforma y, por consiguiente, no hay diferencias con el sistema penitenciario común.

En relación con la segunda de las cuestiones sobre que se debe entender por «juez encargado del cumplimiento de la Sentencia» pudiera suscitarse una doble interpretación:

33 La disposición adicional 5. ${ }^{\text {a }}$ de la Ley Orgánica 6/1985 del Poder judicial, de 1 de julio, ha sido modificada por la Ley Orgánica 7/2003, de 30 de junio, de medidas de reforma para el cumplimiento íntegro y efectivo de las penas que introdujo el punto 6. ${ }^{\circ}$ En la redacción actual se dice:

«1. El recurso de reforma podrá interponerse contra todos los autos del Juez de Vigilancia Penitenciaria». 
- Que se trata del órgano que dictó la Sentencia.

- Que en sentido literal, otro órgano judicial pudiera tener competencia exclusiva para la materia de ejecución, como ocurre habitualmente en la jurisdicción ordinaria.

A mi entender, la primera de las posibilidades es factible pero, en todo caso, debe descartarse la segunda hipótesis por cuanto la jurisdicción militar, al no tener actualmente un excesivo volumen de asuntos, no justifica que se atribuyan las ejecuciones con carácter exclusivo a un órgano judicial, siendo precisamente este el criterio que tiene en cuenta la jurisdicción ordinaria para atribuir funciones exclusivas de ejecución a un juzgado o a varios descongestionado así el trabajo de muchos otros, dando así agilidad al sistema.

Sin embargo la explicación de cuál será el órgano que conozca del recurso de apelación frente a resoluciones derivadas del Juez de Vigilancia y al que se atribuye la mención «juez encargado del cumplimiento de la Sentencia», puede deducirse con total claridad del contenido del art. 342 de la LPM, ya que permite al Tribunal Militar Central en los procedimientos de instancia única en los que haya intervenido, encargar la ejecución de la Sentencia al Tribunal Territorial donde se deba de cumplir.

Por lo tanto, la expresión que utiliza el art. 358 de la LPM de «juez encargado del cumplimiento de la Sentencia» debe reputarse comprendida en el órgano que haya dictado la Sentencia o en un Tribunal Militar Territorial por delegación del Tribunal Militar Central.

Por otro lado, la disposición Adicional quinta de la LOPJ frente a recursos contra resoluciones del JVP parece distinguir entre materias relativas a la ejecución y otras derivadas de régimen de cumplimiento, siendo que en las primeras corresponde conocer la apelación al Tribunal Sentenciador en tanto que en las segundas corresponde a la Audiencia Provincial correspondiente a la demarcación judicial donde radique el establecimiento penitenciario.

En concreto, en los recursos de apelación contra resoluciones dictadas por el Juez de Vigilancia en materia de régimen, se situarían en general todas aquellas quejas contra decisiones de la administración penitenciaria por los motivos más variados, entre los que despuntan los de la denegación de permisos de salida.

En materia de régimen también se comprenden los recursos contra sanciones disciplinarias, cuya revisión en alzada corresponde al Juez de Vigilancia sin ulterior recurso. 
El art. 44.3 de la LOGP señala que «la interposición de recurso contra resoluciones sancionadoras suspenderá la efectividad de la sanción, salvo cuando por tratarse de un acto de indisciplina grave la corrección no pueda demorarse. Los recursos contra resoluciones que impongan la sanción de aislamiento en celda serán de tramitación urgente y preferente».

Los recursos contra actos de ejecución, son los que se refieren a la clasificación y denegación de la libertad condicional, de tal manera que del recurso de apelación frente a resoluciones dictadas por el JVP conocerá el Tribunal Sentenciador.

El punto $8^{\text {a }}$ de la Disposición Adicional $5^{\text {a }}$ de la de la LOPJ indica, además de señalar la legitimación del Ministerio Fiscal, del penado o en su caso del liberado condicional ${ }^{34}$, que se siga para el recurso de apelación la tramitación de las normas del procedimiento abreviado.

Y ello, a nuestro parecer, en ningún caso, debería ser contradictorio con el contenido del art. 358 de la LPM.

En una interpretación integradora, el JVPM, después de cumplir con la tramitación de los art. 766 y siguientes de la LECrim, de subsidiaria aplicación a la LPM, dictará auto admitiendo el recurso y remitiendo el asunto para su debida decisión al órgano competente para la definitiva resolución de la apelación. En otro caso, denegará la apelación, lo que podría dar lugar a la interposición de recurso de queja, a resolver por el órgano judicial al que correspondería la apelación.

De todo lo anterior y llevado al campo del derecho castrense, teniendo en cuenta que la única prisión militar actualmente existente es la de Alcalá de Henares, en donde se alojan militares tanto por delitos propiamente militares como por delitos comunes, el JVPM conocería de todas las incidencias, tanto regimentales como en materia de ejecución.

Siguiendo con la materia que nos ocupa y precisando más la competencia territorial del recurso de apelación en materias de régimen, conocería el Tribunal Militar Territorial n. ${ }^{\circ}$ 1, al corresponder a la demarcación en la que radica el EPM de Alcalá de Henares.

Y de los recursos en materia de ejecución, de los que habitualmente los más frecuentes serán frente a actos clasificatorios, corresponderá a los distintos Juzgados o Tribunales que hubieren dictado

${ }^{34}$ Lo que no se indica en el art. 358 de la LPM aunque resulta evidente en un posible recurso contra la revocación de la libertad condicional, por ejemplo. 
la Sentencia de la que dimane la ejecución, que podrán ser órganos civiles y militares, incluso dentro de los primeros, órganos unipersonales y, como ya señalamos, conforme con la facultad de delegación contemplada en el art. 342 de la LPM que tiene el Tribunal Militar Central en los procedimientos de instancia única en los que haya intervenido y de hacer uso de la misma correspondería al Tribunal Militar Territorial n. ${ }^{\circ} 1$ por cuanto en su competencia territorial radicaría el EPM de Alcalá de Henares en donde se deba de cumplir la Sentencia.

Finalmente diremos que la Disposición Adicional 5. ${ }^{a}$ de la LOPJ en su punto $8 .^{\circ}$ prevé la posibilidad de plantear un recurso de casación por unificación de doctrina, en los casos que no quepa recurso de casación ordinario, estando legitimados para ello el Ministerio Fiscal y el letrado del penado y de los que conocerá la Sala de lo Penal del TS.

Este recurso de casación atípico, que se prevé cuando haya distintas resoluciones contradictorias, no alcanzará a las situaciones creadas por las sentencias precedentes a la impugnada y entendemos que es de plena aplicación respecto de militares penados que cumplan Sentencia por delitos comunes en el EPM de Alcalá de Henares.

Ahora bien, también consideramos que este recurso atípico de Casación, de acuerdo con el principio pro actione, el principio de igualdad y el derecho a la tutela judicial efectiva, es de aplicación para los penados por delitos militares, siendo que su conocimiento en este caso correspondería a la Sala de lo Militar y no a la Sala de lo Penal del TS.

Y si el recurso de Casación por unificación de doctrina tiene fundamento en posibles contradicciones de las resoluciones judiciales castrenses, derivarían básicamente de los distintos criterios que pudieran tener los Tribunales Militares Territoriales o entre éstos y las del Tribunal Militar Central en recursos derivados de ejecución porque en materia de régimen no habría posible contradicción, ya que toda la materia y mientras sólo haya un EPM radicado en Alcalá de Henares, será de la competencia exclusiva del Tribunal Militar Territorial $n .^{\circ} 1$.

Y para terminar finalmente señalaremos que frente a la resolución que se dicte por el Tribunal fijando el límite máximo de cumplimiento conforme con el art. 345 de la LPM, cabe que por el Fiscal Jurídico Militar o por el condenado se puedan interponer recurso de casación por infracción de Ley. 


\section{CONCLUSIONES}

1. ${ }^{\mathrm{a}}$ El reconocimiento constitucional de la jurisdicción castrense no implica que bajo la excusa de la especialidad militar se sitúe a la administración castrense al margen de las garantías constitucionales o que la administración militar sea un compartimento estanco ajeno al control judicial.

2. ${ }^{\mathrm{a}} \quad$ Las funciones del JVP en el ámbito militar se atribuyen a los miembros del Cuerpo Jurídico Militar, los cuales pertenecen a los Cuerpos Comunes de las FFAA con empleo o rango propio.

3. ${ }^{\text {a }}$ Aunque los Jueces que realizan funciones en el JVPM estén integrados en el poder judicial lo cierto es que no tienen ninguna representación en el Consejo General del Poder Judicial.

4. ${ }^{\text {a }}$ De acuerdo con la Ley de la Carrera Militar, mientras realizan funciones propias de la jurisdicción militar se encuentran en activo, en tanto que si desempeñan funciones en el TS o en otros organismos jurisdiccionales se encuentran en situación de servicios especiales.

5. ${ }^{\text {a }}$ Los JVPM están más próximos a un órgano de carácter administrativo que judicial y, en este sentido, no consideramos que puedan ser una pieza clave en el sistema para la salvaguarda de derechos y corrección de los abusos y desviaciones que pudieran producirse en el sistema penitenciario castrense.

6. ${ }^{\mathrm{a}}$ Consideramos de lege ferenda que debería de acometerse una reforma que atribuyera en situaciones de plena normalidad a los juzgados y Tribunales ordinarios las funciones que actualmente detentan los JVPM, lo que daría mayor coherencia y credibilidad al sistema penitenciario militar español.

7. $\quad$ El JVPM, o al juzgado al que se le atribuyeran estas competencias debería de asumir estas funciones sólo en casos extremos, como es tiempo de guerra o el estado de excepción o sitio.

8. ${ }^{\text {a }}$ En ningún caso, pueden existir vacíos dentro del sistema penitenciario militar español que impliquen una merma en el derecho a la tutela judicial efectiva.

9. ${ }^{\text {a }}$ Si existe un militar interno por motivos penales en una unidad distinta al único EPM actualmente existente, podrá ejercitar con plenitud todos sus derechos derivados de vigilancia penitenciaria, bien ante el JVP correspondiente al lugar en donde se encuentre si estuviera por decisión de la autoridad judicial ordinaria o bien ante 
el Juzgado Togado Militar correspondiente, en caso de internamiento por autoridad judicial militar.

$10 .^{a} \quad$ En materia de recursos deben admitirse un sistema que facilite el principio pro actione $\mathrm{y}$, en general, la doble instancia, admitiéndose recursos inicialmente no previstos en la LPM, tal como el recurso de reforma o el llamado recurso de casación por unificación de doctrina, por integración con las reformas de la legislación común.

\section{BIBLIOGRAFÍA}

CLAVER VALDERAS, JOSÉ MANUEL. Comunicación. Aplicabilidad de penas por el trabajo a los internos en establecimientos penitenciarios militares. Derecho Penal y Procesal Militar. Consejo General del Poder Judicial. 1993, pág. 766.

FERNÁNDEZ BENITO, ALFREDO. Comunicación. La determinación del Estatuto Personal de Vocales y Jueces Togados: Un imperativo constitucional. La jurisdicción Militar. Consejo General del Poder Judicial. 1992, pág. 158.

GARCÍA VALDÉS, C. Derecho Penitenciario Militar: una aproximación histórica. Derecho Penitenciario (Escritos 1982-1989). Ministerio de Justicia. Madrid 1989.

JIMÉNEZ VILLAREJO, J. El cumplimiento de las penas privativas de libertad en el ámbito militar. Ponencia desarrollada en la III jornada de Fiscales de Vigilancia Penitenciaria. 18-20 Septiembre 1991.

PÉREZ ESTEBAN, F., El Derecho Penitenciario Militar. Derecho Penal y Procesal Militar. Consejo General del Poder Judicial. Madrid 1993.

\section{ABREVIATURAS UTILIZADAS}

Art. Artículo.

BOE Boletín Oficial del Estado.

CE Constitución Española.

CP Código Penal.

CPM Código Penal Militar. 
EPM Establecimiento Penitenciario Militar.

FFAA Fuerzas Armadas.

JVP Juez de Vigilancia Penitenciaria.

JVPM Juez Togado Territorial Militar con funciones de Vigilancia.

LOCO Ley Orgánica de la Competencia y Organización de la Jurisdicción Militar.

LECrim Ley Enjuiciamiento Criminal.

LO Ley Orgánica.

LOGP Ley Orgánica General Penitenciaria.

LOPJ Ley Orgánica del Poder Judicial.

LPM Ley Orgánica Procesal Militar.

Núm. Número.

OM Orden Ministerial.

RD Real Decreto.

RP Reglamento Penitenciario.

RPM Reglamento de Establecimientos Penitenciarios Militares.

STC Sentencia del Tribunal Constitucional.

STS Sentencia del Tribunal Supremo.

TC Tribunal Constitucional.

TS Tribunal Supremo. 
